\title{
Incipient speciation in the flour beetle, Tribolium confusum: premating isolation between natural populations
}

\author{
MICHAEL J. WADE*, NANCY W. CHANG \& MICHAEL MCNAUGHTON \\ Department of Ecology and Evolution, 1101 E. 57th Street, University of Chicago, Chicago, IL 60637, U.S.A.
}

\begin{abstract}
We report the existence of partial reproductive isolation between two natural populations of the flour beetle, Tribolium confusum, collected in Kaduna, Nigeria and Zagreb, Croatia. When a female from either population is paired with a single sympatric or allopatric male, she produces near normal numbers of semifertile offspring. However, when females are multiply mated with allopatric and sympatric males, the sympatric males sire the large majority of offspring. When measured in offspring numbers, the mean relative fitness of allopatric males is 0.425 with Nigerian females and 0.085 with Croatian females. Thus, the reproductive isolation is reciprocal but asymmetric. Behavioural observations indicate that only a fraction of mating attempts by allopatric males are successful because females do not become quiescent as often when mounted by allopatric males. The premating isolation is also reciprocal but asymmetric: Nigerian females are more accepting of allopatric males as mates than are Croatian females. The prezygotic behavioural isolation between these two populations is different from the postmating, prezygotic isolation observed between two other species in the genus, $T$. castaneum and $T$. freemani. Furthermore, the $T$. confusum interpopulation hybrids are fertile although they exhibit a weak female bias.
\end{abstract}

Keywords: female mate choice, incipient speciation, premating reproductive isolation, Tribolium confusum.

\section{Introduction}

The process of speciation converts genetic variation within populations into permanent genetic variation between populations (Lewontin, 1974). The acquisition of an intrinsic genetic mechanism for reproductive isolation between populations is a landmark event in the speciation process because, by restricting further gene flow, all subsequent genetic changes occur independently in different populations and are diversifying. Reproductive isolation is generally thought to develop by the gradual accumulation of genetic differences between populations as a byproduct of other adaptive or neutral genetic changes in allopatry (Dobzhansky, 1937; Muller, 1942; Mayr, 1963; Charlesworth et al., 1987; Coyne, 1992, 1993; Wu \& Davis, 1993). Some subset of these changes within populations is believed to confer incompatibility when combined by hybridization between the populations.

Premating barriers to gene flow are believed to

\footnotetext{
${ }^{*}$ Correspondence.
}

arise frequently between allopatric populations (Mayr, 1963) owing to sexual selection (Kaneshiro, 1983) or random genetic drift (Carson \& Templeton, 1984). We report our finding of partial and reciprocal prezygotic reproductive isolation between allopatric populations of Tribolium confusum recently collected from Kaduna, Nigeria and Zagreb, Croatia. This beetle is a human commensal pest found worldwide in grain and other stored products (Sokoloff, 1974). This species has been placed in a separate clade from the $T$. castaneum species group, which includes $T$. freemani, based upon morphological, genetic, karyotypic and molecular data (Hinton, 1948; Sokoloff, 1974; Brownlee \& Sokoloff, 1988; Juan et al., 1993; Wade \& Johnson, 1994). The sterile interspecific hybrids between $T$. castaneum and $T$. freemani have been studied in a series of papers (Wade et al., 1993, 1994; Robinson et al., 1994; Wade \& Johnson, 1994). These two species exhibit reciprocal postmating, prezygotic reproductive isolation (Robinson et al., 1994; Wade et al., 1994). T. confusum has not been reported to hybridize with other species in the genus nor has reproductive iso- 
lation among different populations of this species been reported.

Mating in $T$. confusum occurs without elaborate courtship and the average copulation duration is 45 seconds (Park, 1933; Shrode, 1960; Sokoloff, 1974). Both sexes will mate several times an hour (Park, 1933). Males appear to exhibit indiscriminate mating and will 'attempt copulation with other males, dead beetles of both sexes, or with any object, such as a lump of flour of frass, which looks like a beetle' (Sokoloff, 1974, p. 201). Premating reproductive isolation between species has not been reported in the genus or between allopatric populations of the same species although frequency-dependent differences in mating and fertilization success between male genotypes have been reported for both $T$. castaneum and T. confusum (Sinnock, 1970; Vardell \& Brower, 1978; Lewis \& Austad, 1990).

\section{Materials and methods}

In a series of experiments, we investigated two recently collected, wild strains of $T$. confusum: (1) the b-Nigeria stock $(\mathrm{Ng})$ was established by mass mating $40+$ adults collected in 1993 in Kaduna State, Nigeria, by Mr David Adebote; and (2) the bCroatia stock (Cr) was established from $30+$ adult beetles collected in Zagreb in 1979. Mating tests and the polymerase chain reaction using diagnostic primers (Wade \& Chang, 1995) indicated that the $\mathrm{Ng}$ strain does not harbour the endosymbiont, $\mathrm{Wol}$ bachia pipientis, and, in these experiments, we used a strain of $\mathrm{Cr}$ that had been cured of this endosymbiont (Wade \& Stevens, 1985; Stevens \& Wade, 1990; Wade \& Chung, 1995). The Cr stock is also segregating at an autosomal locus for alleles affecting body colour (Wade \& Chang, 1995). In these experiments, we used $\mathrm{Cr}$ beetles homozygous, or $b / b$, for the black body colour. This body colour marker does not appear to have significant fitness effects at the frequencies and densities studied here (cf. Fig. 1 in Wade \& Chang, 1995). All adults used in these experiments were between 14 and 45 days post eclosion. The standard medium used throughout these experiments consists of 95 per cent stone-ground whole wheat flour, 5 per cent dried brewer's yeast, and 0.03 per cent fumagillin by weight.

We conducted three kinds of experiments. In the Single-male Experiments, we mated single $\mathrm{Ng}$ or $\mathrm{Cr}$ females to single $\mathrm{Ng}$ or $\mathrm{Cr}$ males and permitted the pairs to produce progeny for 30 days in an 8 dram vial with $8 \mathrm{~g}$ of standard medium. These were 10 replicates of each of the four possible pairings (Male $\times$ Female: $\mathrm{Ng} \times \mathrm{Ng}, \quad \mathrm{Ng} \times \mathrm{Cr}, \quad \mathrm{Cr} \times \mathrm{Ng}$,
$\mathrm{Cr} \times \mathrm{Cr}$ ). After an additional 25-day maturation period, the progeny were censused and separated by sex. Adult progeny were sexed by pressing on the abdomen with a forceps and everting the genitalia; pupae were separated by the external genitalia. The fertility of the 'hybrid' or interstrain progeny (offspring of the $\mathrm{Ng} \times \mathrm{Cr}$ and $\mathrm{Cr} \times \mathrm{Ng}$ crosses) was tested in two ways. Male and female hybrids were confined together and offspring production was noted. In a separate study, single hybrid males from the $\mathrm{Ng} \times \mathrm{Cr}$ cross were mated to single $\mathrm{Ng}$ and $\mathrm{Cr}$ virgin females in an 8 dram vial with $8 \mathrm{~g}$ of standard medium for 30 days.

In the Multiple-male Experiments, we mated single virgin females of each strain to $1,2,4$ or 6 males. We varied the numbers of $\mathrm{Ng}$ and $\mathrm{Cr}$ males, $(\mathrm{Ng}$, $\mathrm{Cr}$ ), in the following way: (a) the one-male treatments, $(0,1),(1,0)$; (b) the two-male treatments, $(0$, $2),(1,1),(2,0)$; (c) the four-male treatments, $(1,3)$, $(2,2),(3,1)$; and (d) the six-male treatments, $(1,5)$, $(3,3)$, and $(5,1)$. Virgin males and females were isolated from both strains at the pupal stage. The females were placed first into 8 dram vials containing $8 \mathrm{~g}$ of standard medium and the males in the specific configurations were added subsequently. The vials were stoppered and husbanded in a darkened incubator maintained at the standard conditions of $29^{\circ} \mathrm{C}$ and 70 per cent relative humidity. After two weeks, the adults were sifted from the medium, transferred to a fresh vial of medium, and permitted to reproduce for a second two-week period. All adults were sifted from these second vials after two weeks. After a maturation period of approximately 40 days, the progeny in each vial were censused and genotyped. In the $\mathrm{Cr}$ female treatments, all $+/ b$ heterozygous progeny were sired by the $\mathrm{Ng}$ males while all $b / b$ progeny were sired by the $\mathrm{Cr}$ males. In the $\mathrm{Ng}$ female treatments, all heterozygous $+/ b$ progeny were sired by the $\mathrm{Cr}$ males while all homozygous $+1+$ progeny were sired by the $\mathrm{Ng}$ males. Thus, in both cases, the offspring of the allopatric male were $+/ b$ heterozygotes. There were five replicates of each male configuration for each type of female (two types of females $\times 11$ male configurations per type of female $\times$ five replicates per configuration $\times$ two 2-week observations per replicate $=220$ observations total).

In the Mating Behaviour Experiments, we set up arenas consisting of $30 \mathrm{Ng}$ males, $30 \mathrm{Ng}$ females, 30 $\mathrm{Cr}$ males and $30 \mathrm{Cr}$ females in $5 \mathrm{~cm}$ diameter glass petri dishes with a thin layer $(0.95 \mathrm{~cm})$ of medium. Males were marked on the elytra with a silver or gold FaberCastell PX-21 marker. Females were added to the arenas first, approximately $24 \mathrm{~h}$ before 
adding the males. For $2 \mathrm{~h}$ after adding the males, all copulation attempts (male mountings of females) and successful copulations (intromissions) were observed and recorded.

\section{Results}

\section{Single-male experiments}

In Table 1, we report the average number of offspring produced in a 30-day period by single pairs of adult beetles. An ANOva of the natural log transformed data indicates significant sire effects (error and interaction mean squares pooled: $P<0.0001$, $F_{1,36}=41.07$ ) but no effects of dam or sire $\times$ dam interaction. The offspring of the interstrain crosses appeared normally fertile. All hybrid vials produced abundant offspring indicating that hybrids of both sexes are fertile. Furthermore, 30 of $30(\mathrm{Ng} \times \mathrm{Cr})$ hybrid males produced offspring with $\mathrm{Cr}$ females and 28 of 38 produced offspring with $\mathrm{Ng}$ females. The average number of offspring produced per $(\mathrm{Ng} \times \mathrm{Cr}) \times \mathrm{Cr}$ pair, 74.7 (SE 9.0), was almost exactly intermediate between the numbers of offspring produced by a $\mathrm{Cr}$ female when mated to an $\mathrm{Ng}$ male and to a $\mathrm{Cr}$ male (78.7 see Table 1, column 2), suggesting that the sire effect on female productivity may be heritable. These observations demonstrate that adults from these two allopatric populations can be crossed to yield abundant and fertile offspring.

We also investigated the sex ratios of the pure strain and interstrain offspring. To obtain large sample sizes, we pooled data from these crosses with the $(1,1)$ crosses from the Multiple-male Experiments (see below). Only the offspring from the $\mathrm{Ng} \times \mathrm{Cr}$ cross showed a weak but statistically significant bias toward hybrid females (Table 2). This bias is weaker than any reported for hybrids from crosses

Table 1 Mean $(X)$ and standard error (SE) of offspring numbers produced by crosses between single pairs of males and females of Tribolium confusum from Nigeria and Croatia

\begin{tabular}{lccc}
\hline & \multicolumn{2}{c}{ Females } & \\
\cline { 2 - 4 } Males & Nigeria & Croatia & \\
& $X$ & $X$ & Average \\
\hline Nigeria & 52.3 & 58.8 & 55.6 \\
& $(4.6)$ & $(5.6)$ & \\
Croatia & 88.6 & 98.5 & 93.6 \\
& $(6.6)$ & $(5.1)$ & \\
Average & 70.5 & 78.7 & 74.6 \\
\hline
\end{tabular}

between $T$. castaneum males and $T$. freemani females but equivalent to that reported for the cross between $T$. freemani males and females from a mutant strain (c-pl) of T. castaneum (cf. Table 2 in Wade \& Johnson, 1993).

\section{Multiple-male experiment}

The numbers of offspring sired by the allopatric and sympatric males for each type of female are given in Table 3 as the average numbers of offspring produced per 2 weeks per replicate per treatment with one standard error (SE). We pooled the two observation periods because the average treatment difference in productivity between the first and second periods was only 1.10 offspring (4.83 SE). The $\mathrm{Ng}$ females produced an average of 111.1 offspring in 14 days with a single sympatric male, comparable to and not statistically different from the average number of offspring that an $\mathrm{Ng}$ female produces with an allopatric $\mathrm{Cr}$ male, 115.4, in the same period of time. The productivity of single pairs permitted to reproduce for 30 days is less than that of single pairs permitted to reproduce for 14 days (compare Tables 1 and 3 ). When adults are permitted to reproduce in a vial for a limited period, a more uniformly aged cohort of developing larvae results. This changes many of the density-dependent effects which occur when adults are permitted a longer period of reproduction and the resulting population consists of a mixed age cohort of adults, large larvae, small larvae, and eggs (Wade, 1976; McCauley \& Wade, 1980).

We conclude from these offspring numbers and those in Table 1 that the $\mathrm{Ng}$ and $\mathrm{Cr}$ geographical strains are fully interfertile. However, when one $\mathrm{Ng}$ male and one $\mathrm{Cr}$ male are present simultaneously, the sympatric $(\mathrm{Ng})$ male sires 87 per cent of the progeny. Indeed, in every treatment, the sympatric $(\mathrm{Ng})$ males sire many more progeny than would be expected based on their relative numbers. Whenever

Table 2 The sex ratio (sample size) of intrastrain and interstrain offspring of Tribolium confusum

\begin{tabular}{llc}
\hline & \multicolumn{2}{c}{ Female parent } \\
\cline { 2 - 3 } Male parent & Nigeria & Croatia \\
\hline Nigeria & 0.483 & 0.498 \\
& $(1030)$ & $(548)$ \\
Croatia & $0.530^{*}$ & 0.524 \\
& $(1947)$ & $(1215)$ \\
\hline${ }^{*} P<0.01$. & &
\end{tabular}


Table 3 Mean $(X)$ and standard error (SE) of offspring numbers sired by Tribolium confusum males from Nigeria $(\mathrm{Ng})$ and Croatia $(\mathrm{Cr})$ crossed to either a single $\mathrm{Ng}$ female or a single $\mathrm{Cr}$ female

Nigerian female

No. of males

\begin{tabular}{|c|c|c|c|c|c|c|c|}
\hline \multirow{2}{*}{$\begin{array}{l}\text { Sympatric } \\
\text { Ng }\end{array}$} & \multirow{2}{*}{$\begin{array}{l}\text { Allopatric } \\
\text { Cr }\end{array}$} & \multicolumn{2}{|c|}{ Sympatric male } & \multicolumn{2}{|c|}{ Allopatric male } & \multicolumn{2}{|c|}{ Total } \\
\hline & & $X$ & (SE) & $X$ & $(\mathrm{SE})$ & $X$ & (SE) \\
\hline 1 & 0 & 111.1 & $(12.2)$ & - & - & 111.1 & (12.2) \\
\hline 2 & 0 & 103.5 & $(7.3)$ & - & - & 103.5 & $(7.4)$ \\
\hline 0 & 1 & - & - & 115.4 & (17.6) & 115.4 & (17.7) \\
\hline 0 & 2 & - & - & 89.8 & $(9.2)$ & 89.8 & $(9.2)$ \\
\hline 1 & 1 & 87.7 & $(7.6)$ & 13.3 & (5.5) & 101.0 & (12.6) \\
\hline 3 & 1 & 63.7 & (9.4) & 3.1 & (1.4) & 66.8 & (10.4) \\
\hline 2 & 2 & 63.2 & $(15.2)$ & 18.0 & (6.6) & 81.2 & (13.3) \\
\hline 1 & 3 & 75.9 & $(6.9)$ & 18.0 & (7.3) & 93.9 & (3.5) \\
\hline 5 & 1 & 63.3 & (7.4) & 11.6 & (9.7) & 74.9 & (14.3) \\
\hline 3 & 3 & 52.6 & $(13.0)$ & 19.9 & (6.9) & 72.5 & (9.9) \\
\hline 1 & 5 & 45.1 & $(9.1)$ & 44.3 & $(9.5)$ & 89.4 & $(0.8)$ \\
\hline
\end{tabular}

Croatian female

No. of males

\begin{tabular}{|c|c|c|c|c|c|c|c|}
\hline \multirow{2}{*}{$\underset{\mathrm{Cr}}{\text { Sympatric }}$} & \multirow{2}{*}{$\begin{array}{l}\text { Allopatric } \\
\mathrm{Ng}\end{array}$} & \multicolumn{2}{|c|}{ Sympatric male } & \multicolumn{2}{|c|}{ Allopatric male } & \multicolumn{2}{|c|}{ Total } \\
\hline & & $X$ & $(\mathrm{SE})$ & $X$ & (SE) & $X$ & $(\mathrm{SE})$ \\
\hline 1 & 0 & 86.3 & (15.3) & - & - & 86.3 & $(15.3)$ \\
\hline 2 & 0 & 78.9 & $(10.0)$ & - & - & 78.9 & (10.0) \\
\hline 0 & 1 & - & - & 43.3 & $(10.3)$ & 43.3 & (10.3) \\
\hline 0 & 2 & - & - & 45.1 & (19.1) & 45.1 & (19.1) \\
\hline 1 & 1 & 60.9 & $(9.4)$ & 0.8 & $(0.4)$ & 61.7 & $(9.7)$ \\
\hline 3 & 1 & 60.4 & $(11.0)$ & 1.0 & $(0.5)$ & 61.4 & $(10.7)$ \\
\hline 2 & 2 & 68.8 & (18.1) & 1.8 & (1.2) & 70.5 & (18.9) \\
\hline 1 & 3 & 76.3 & $(5.0)$ & 4.7 & (2.5) & 81.0 & $(6.8)$ \\
\hline 5 & 1 & 81.8 & $(4.4)$ & 3.1 & (1.6) & 84.9 & (5.7) \\
\hline 3 & 3 & 65.8 & $(10.2)$ & 2.3 & $(0.6)$ & 68.1 & $(10.8)$ \\
\hline 1 & 5 & 65.3 & $(6.6)$ & 4.6 & (1.7) & 69.9 & $(5.1)$ \\
\hline
\end{tabular}

Offspring paternity allopatric and sympatric males are present simultaneously, the allopatric male produces fewer progeny than expected (see Table 3, column in bold).

A Croatian female produces twice as many offspring with a sympatric $(\mathrm{Cr})$ male as with an allopatric $(\mathrm{Ng})$ male (86.3 vs. 43.3 , respectively). However, similar to the $\mathrm{Ng}$ females, whenever allopatric and sympatric males are present simultaneously with a $\mathrm{Cr}$ female, the allopatric male(s) sire very few offspring, only 1-3 per $\mathrm{Ng}$ male (cf. lower half of Table $3)$. The reduction in offspring numbers of the allopatric males is proportionately greater for $\mathrm{Cr}$ females than it is for Nigerian females.
These populations exhibit partial reciprocal reproductive isolation from one another when both allopatric and sympatric males are present but not when confined in the so-called 'no choice' situation (Coyne, 1993; Scott, 1994) with only allopatric males. The reduction in relative fitness of allopatric males when in direct reproductive competition with sympatric males is large (Table 4). The relative fitness of allopatric males varies with male density. The reduction is greatest when there are two males and smallest when there are six competing males. There are no trends, such as one that might favour a rare male type, within densities. 
Table 4 Mean relative fitness $(X)$ and standard error (SE) of allopatric males of Tribolium confusum mating with either a Nigerian female $(\mathrm{Ng})$ or a Croatian female $(\mathrm{Cr})$ measured by relative paternity of offspring

\begin{tabular}{|c|c|c|c|c|c|}
\hline & & \multicolumn{4}{|c|}{ Relative fitness of an allopatric male } \\
\hline \multicolumn{2}{|c|}{ Number of males } & \multicolumn{2}{|c|}{$\mathrm{Ng}$ female } & \multicolumn{2}{|c|}{$\mathrm{Cr}$ female } \\
\hline Sympatric & Allopatric & $X$ & $(\mathrm{SE})$ & $X$ & $(\mathrm{SE})$ \\
\hline 1 & 1 & 0.233 & $(0.083)$ & 0.022 & $(0.012)$ \\
\hline Mean $2 \mathrm{~m}$ & & 0.233 & & 0.022 & \\
\hline 3 & 1 & 0.164 & $(0.081)$ & 0.085 & $(0.046)$ \\
\hline 2 & 2 & 0.483 & $(0.162)$ & 0.046 & $(0.038)$ \\
\hline 1 & 3 & 0.230 & $(0.119)$ & 0.073 & $(0.038)$ \\
\hline Mean $4 \mathrm{~m}$ & & 0.292 & & 0.068 & \\
\hline 5 & 1 & 0.696 & $(0.567)$ & 0.209 & $(0.094)$ \\
\hline 3 & 3 & 0.580 & $(0.244)$ & 0.063 & $(0.011)$ \\
\hline 1 & 5 & 0.592 & $(0.124)$ & 0.087 & $(0.046)$ \\
\hline \multicolumn{2}{|c|}{ Mean 6 males } & 0.621 & & 0.120 & \\
\hline \multicolumn{2}{|c|}{ Mean relative fitness } & 0.425 & & 0.084 & \\
\hline
\end{tabular}

Table 5 Mating attempts and copulations by Tribolium confusum observed in a two-hour period between 30 males from Nigeria and 30 males from Croatia with either 30 Nigerian females or 30 Croatian females

\begin{tabular}{lcccccc}
\hline & \multicolumn{4}{c}{ Males } & \\
\cline { 2 - 3 } \cline { 5 - 6 } Females & Attempts & Copulations & & Attempts & Copulations & $\begin{array}{c}\text { Allopatric } \\
\text { relative } \\
\text { fitness }\end{array}$ \\
\cline { 2 - 3 } Nigeria & 22 & 22 & & 9 & 9 & 0.581 \\
Croatia & 11 & 0 & & 29 & 29 & 0.000 \\
\hline
\end{tabular}

\section{Discussion}

The reduced fitness of allopatric males in the presence of sympatric males appears to result from aspects of premating mate choice by females that favour sympatric over allopatric mates. It could also be owing to differences occurring during very early courtship (Eberhard, 1994). In contrast, fertilization in interpopulation pairings in the absence of sympatric males is normal because we observed no differences between females paired with single allopatric or sympatric males (Table 1). The only significant differences among single-pair productivities was between $\mathrm{Ng}$ and $\mathrm{Cr}$ males. Hybrid $(\mathrm{Ng} \times \mathrm{Cr})$ males produced intermediate numbers of offspring when crossed to $\mathrm{Cr}$ females indicating a heritable basis of this sire effect on offspring numbers. We observed no postmating reproductive isolation between populations in this species of flour beetles.

These findings are different from those previously reported in crosses between two other species in this genus, T. castaneum and T. freemani. In this pairing, the isolation is postmating but prezygotic (Wade $e t$ al., 1993; Robinson et al., 1994) and hybrids of both sexes are sterile (Wade \& Johnson, 1994). Furthermore, the interspecific hybrids exhibit Haldane's rule in that hybrid males are infrequent and also tend to be morphologically deformed (Wade et al., 1994). In one respect, however, the findings are similar. When females are not given a choice of mates, interspecific pairs produce normal numbers of offpsing. The pre- 
zygotic isolation appears only when females are presented with males of both species as mates. Similar studies in crickets (Howard \& Gregory, 1993), grasshoppers (Hewitt et al., 1989; Bella et al., 1992), and some plants (Walsh \& Charlesworth, 1992), indicate that some kinds of prezygotic isolation can be detected only in 'choice' experiments where more than one kind of male is available for mating or fertilization. No-choice tests for isolation can be effective in some species (e.g. Coyne, 1993; Scott, 1994) but they will overlook the kind of isolation reported here and in these other studies.

For this particular pair of allopatric populations, the isolation is reciprocal but asymmetric. Croatian females are much less accepting of Nigerian males than Nigerian females are of Croatian males. However, the premating isolation is reinforced by postzygotic incompatibility that occurs in the $\mathrm{Cr} \times \mathrm{Ng}$ cross owing to the presence of Wolbachia in the Croatian strain (Stevens \& Wade, 1990) and its absence in the Nigerian strain. With uninfected Nigerian females, the fitness of successfully mating but infected Croatian males would be reduced postmating to zero, a level of isolation comparable to that seen in the reciprocal cross. Furthermore, this microbe-mediated incompatibility does not depend upon the opportunity for female mate choice since it occurs independently of the presence of sympatric Nigerian males. The unidirectional cytoplasmic incompatibility with Wolbachia enhances the barrier to gene flow and makes the reproductive isolation of these two allopatric populations nearly complete and symmetric.

Dobzhansky $(1940,1970)$ presented the 'reinforcement' model, in which natural selection can play a direct role in establishing premating reproductive isolation between populations once partial but not complete postmating reproductive isolation had arisen by the pleiotropic effects of other adaptive or neutral changes. Although the importance of Dobzhansky's reinforcement model for the evolution of reproductive isolation between natural populations remains controversial (Littlejohn, 1981; Butlin, 1987, 1989; Coyne \& Orr, 1989; Howard, 1993), it is not very important in this instance because we observed no postmating reproductive isolation between these two populations. It is an example of prezygotic isolation arising in allopatry prior to detectable postmating isolation.

\section{Acknowledgements}

We thank Theresa Robinson for assistance in the experiments and the following for comments on and/ or discussions of the manuscript: John Kelly, Alan Molumby, Mohamed Noor, Mike Palopoli, Chung-I $\mathrm{Wu}$, and an anonymous referee. This work has been supported by a National Institutes of Health grant (GM 22523) to M.J.W.

\section{References}

BELLA, J. L., BUTLIN, R. K., FERRIS, C. AND HEWITT, G. M. 1992. Asymmetrical homogamy and unequal sex ratio from reciprocal mating-order crosses between Chorthippus parallelus subspecies. Heredity, 68, 345-352.

BROWNLEE, A. AND SOKOLOFF, A. 1988. Transmission of Tribolium castaneum (Herbst) mutants to T. castaneumT. freemani (Hinton) hybrids (Coleoptera: Tenebrionidae) J. Stored Prod. Res., 24, 145-150.

BUTLIN, R. 1987. Speciation by reinforcement. Trends Ecol. Evol., 2, 8-13.

BUTLIN, R. 1989. Reinforcement of premating isolation. In: Otte, D. and Endler, J. A. (eds) Speciation and Its Consequences, pp. 158-179. Sinauer Associates, Sunderland, MA.

CARSON, H. L. AND TEMPLETON, A. R. 1984. Genetic revolutions in relation to speciation phenomena: the founding of new populations. Ann. Rev. Ecol. Syst., 15, 97-131.

CHARLESWORTH, B., COYNE, J. A. AND BARTON, N. H. 1987. The relative rates of evolution of sex chromosomes and autosomes. Am. Nat., 130, 113-146.

COYNE, J. A. 1992. Genetics and speciation. Nature, 355, 511-515.

COYNE, J. A. 1993. The genetics of an isolating mechanism between two sibling species of Drosophila. Evolution, 47, 778-788.

COYNE, J. A. AND ORR, H. A. 1989. Patterns of speciation in Drosophila. Evolution, 42, 362-381.

DOBZHANSKy, тH. 1937. Genetics and the Origin of Species. Columbia University Press, New York.

DOBZHANSKY, TH. 1940. Speciation as a stage in evolutionary divergence. Am. Nat., 74, 312-321.

Dobzhansky, TH. 1970. Genetics and the Evolutionary Process. Columbia University Press, New York

EBERHARD, w. G. 1994. Evidence for widespread courtship during copulation in 131 species of insects and spiders, and implications for cryptic female choice. Evolution, 48, 711-733.

HEWITT, G. M., MASON, P. AND NICHOLS, R. A. 1989. Sperm precedence and homogamy across a hybrid zone in the alpine grasshopper, Podisma pedestris. Heredity, 62 , 343-353.

HinTon, H. E. (1948) A synopsis of the genus Tribolium MacLeay, with some remarks on the evolution of its species-groups (Coleoptera: Tenebronidae). Bull. ent. Res., 39, 13-55.

HOWARD, D. J. 1993. Reinforcement: the origin, dynamics, and fate of an evolutionary hypothesis. In: Harrison, R. G. (ed.) Hybrid Zones and the Evolutionary Process, pp. 118-142. Oxford University Press, Oxford.

HOWARD, D. J. AND GREGORY, P. G. 1993. Post-insemina- 
tion signalling systems and reinforcement. Phil. Trans. R. Soc. B, 340, 231-236.

JuAN, C., VAzQuez, P., Rubio, J. M., PetitPierRe, E. AND HEwITT, G. M. 1993. Presence of highly repetitive DNA sequences in Tribolium flour-beetles. Heredity, 70, 1-8.

KANESHIRO, K. Y. 1983. Sexual selection and the direction of evolution in the biosystematics of Hawaiian Drosophilidae. Ann. Rev. Ent., 28, 161-178.

LEWIS, S. M. AND AUSTAD, S. N. 1990. Sources of intraspecific variation in sperm precedence in red flour beetles. Am. Nat., 135, 351-359.

LEWONTIN, R. C. 1974. The Genetic Basis of Evolutionary Change. Columbia University Press, New York.

LITTLEJOHN, M. J. 1981. Reproductive isolation: a critical review. In: Atchley, W. R. and Woodruff, D. (eds) Evolution and Speciation, pp. 298-334. Cambridge University Press, Cambridge.

MAYR, E. 1963. Animal Species and Evolution. Harvard University Press, Cambridge, MA.

MCCAULEY, D. E. AND WADE, M. J. 1980. Group selection: the genetic and demographic basis for the phenotypic differentiation of small populations of Tribolium castaneum. Evolution, 34, 813-821.

MULLER, H. J. 1942. Isolating mechanisms, evolution, and temperature. Biol. Symp., 6, 71-125.

PARK, T. 1933. Studies in population phyisology. II. Factors regulating initial growth of Tribolium confusum populations. J. Exp. Zool., 65, 17-42.

ROBINSON, T., JOHNSON, N. A. AND WADE, M. J. 1994. Postcopulatory, prezygotic isolation: intraspecific and interspecific sperm precedence in flour beetles, Tribolium spp. Heredity, 73, 155-159.

scort, D. 1994. Genetic variation for female mate discrimination in Drosophila melanogaster. Evolution, 48, $112-121$.

SHRODE, R. R. 1960 . Evidence that mating is random in $T$. castaneum. Tribolium Inf. Bull., 3, 15-16.

SINNOCK, P. 1970. Frequency dependence and mating behavior in Tribolium castaneum. Am. Nat., 104, 469-476.
soKoloff, A. 1974. The Biology of Tribolium, vol. 2. Clarendon Press, Oxford.

STEVENS, L. AND WADE, M. J. 1990. Cytoplasmically inherited reproductive incompatibility in Tribolium flour beetles: the rate of spread and effect on population size. Genetics, 124, 367-372.

VARDELL, H. H. AND BROWER, J. H. 1978. Sperm precedence in Tribolium confusum (Coleoptera: Tenebrionidae). J. Kans. Entomol. Soc., 38, 10-18.

WADE, M. J. 1976. Group selection among laboratory populations of Tribolium. Proc. Natl. Acad. Sci. U.S.A., 73, 4604-4607.

WADE, M. J. AND CHANG, N. W. 1995. Increased male fertility in Tribolium confusum beetles after infection with the intracellular parasite Wolbachia. Nature, 373, 72-74.

WADE, M. J. AND GOODNIGHT, C. J. 1991. Wright's shifting balance theory: an experimental study. Science, 253, 1015-1018.

WADE, M. J. AND JOHNSON, W. A. 1994. Reproductive isolation between two species of flour beetles, Tribolium castaneum and T. freemani: variation within and among geographical populations of T. castaneum. Heredity, 72, 155-162.

WADE, M. J., JOHNSON, N. A. AND WARdLE, G. 1994. Analysis of autosomal polygenic variation for the expression of Haldane's rule in flour beetles. Genetics, 138, 791-799.

WADE, M. J., PATTERSON, H., CHANG, N. W. AND JOHNSON, W. A. 1993. Postcopulatory, prezygotic isolation in flour beetles. Heredity, 72, 163-167.

WADE, M. J. AND STEVENS, L. 1985. Microorganism mediated reproductive isolation in flour beetles (genus Tribolium). Science, 227, 527-528.

WALSH, N. E. AND CHARLESWORTH, D. 1992. Evolutionary interpretations of differences in pollen tube growth rates. Q. Rev. Biol., 67, 19-36.

wU, C.-I AND DAVIS, A. w. 1993. Evolution of postmating reproductive isolation: the composite nature of $\mathrm{Hal}-$ dane's rule and its genetic bases. Am. Nat., 142, $187-212$. 